\title{
ANALISIS KELAYAKAN SARANA DAN PRASARANA PRAKTIK DI \\ BENGKEL TEKNIK KONSTRUKSI BATU DAN BETON \\ SMK NEGERI 5 SURAKARTA
}

\author{
Anisa Putri Rahardiani ${ }^{1}$, Sukatiman ${ }^{2}$, Abdul Haris ${ }^{3}$ \\ Email: anisaputri1316 @gmail.com
}

\begin{abstract}
Abstrak : Tujuan penelitian ini adalah (1). Untuk mengetahui kesesuaian kondisi sarana dan prasarana di bengkel praktik Kompetensi Keahlian Teknik Konstruksi Batu dan Beton SMK Negeri 5 Surakarta dengan standar Peraturan Menteri Pendidikan Nasional No. 40 Tahun 2008. (2) Untuk mengetahui tingkat kelayakan sarana Kompetensi Keahlian Teknik Konstruksi Batu dan Beton SMK Negeri 5 Surakarta dengan standar Peraturan Menteri Pendidikan Nasional No. 40 Tahun 2008. (3) Untuk mengetahui tingkat kelayakan prasarana Kompetensi Keahlian Teknik Konstruksi Batu dan Beton SMK Negeri 5 Surakarta dengan standar Peraturan Menteri Pendidikan Nasional No. 40 Tahun 2008. Penelitian yang digunakan merupakan jenis penelitian deskriptif kualitatif. Data yang dikumpulkan dalam penelitian ini diperoleh dari hasil observasi, wawancara dan dokumentasi terhadap objek penelitian yaitu Sarana dan Prasarana praktik bengkel Teknik Batu dan Beton SMK Negeri 5 Surakarta yang meliputi perabot, peralatan praktik, media pembelajaran, dan perlengkapan lain. Instrumen penelitian menggunakan checklist yang digunakan pada saat observasi dan pedoman untuk wawancara. Data sarana dan prasarana yang diperoleh kemudian dibandingkan dengan standar dalam PERMENDIKNAS No. 40 Tahun 2008 tentang standar sarana dan prasarana Sekolah Menengah Kejuruan/Madrasah Aliyah Kejuruan (SMK/MAK) dan instrumen verifikasi dari BSNP No. 1049-P210/11 Tahun 2010/2011 mengenai instrumen verifikasi SMK/MAK tentang penyelenggaraan ujian praktik kejuruan. Hasil penelitian ini menujukan bahwa: (1). Kondisi rata-rata sarana dan prasarana bengkel Batu dan Beton SMK Negeri 5 Surakarta adalah memenuhi syarat yang tercantum pada Permendiknas No. 40 Tahun 2008. (2). Tingkat kelayakan rata-rata sarana pada bengkel Teknik Batu dan Beton SMK Negeri 5 Surakarta sebesar 83\% sehingga dikategorikan dalam kondisi sangat layak. (3). Tingkat kelayakan rata-rata prasarana pada bengkel Teknik Batu dan Beton SMK Negeri 5 Surakarta sebesar 97\% sehingga dikategorikan dalam kondisi sangat layak.
\end{abstract}

Kata kunci: Kelayakan, Sarana, Prasarana

\footnotetext{
${ }^{1}$ Mahasiswa Pendidikan Teknik Bangunan Fakultas Keguruan dan Ilmu Pendidikan

2 Pengajar Pendidikan Teknik Bangunan Fakultas Keguruan dan Ilmu Pendidikan

3 Pengajar Pendidikan Teknik Bangunan Fakultas Keguruan dan Ilmu Pendidikan
} 


\begin{abstract}
The purpose of this study is (1). To find out the suitability of the condition of facilities and infrastructure at workshop of Competency of Stone and Concrete Construction Engineering Competency of SMK Negeri 5 Surakarta with the standard of PERMENDIKNAS no. 40 year 2008. (2) To know the feasibility level of the facilities in Stone and Concrete Construction Engineering Competency of SMK Negeri 5 Surakarta with the standard of PERMENDIKNAS no.40 year 2008 (3) To know the feasibility level of the infrastructure in Stone and Concrete Construction Engineering Competency of SMK Negeri 5 Surakarta with the standard of PERMENDIKNAS no.40 year 2008. This reseach used deskriptive qualitatif method. The data collected in this study were obtained from the results of observation, interview and documentation of the object of research is the practice facilities workshop which includes furniture, practical equipment, instructional media, and other equipment as well as student practice result. The reserch instrument used a checklist when observation. The data were compare with predermined standards based of PERMENDIKNAS No. 40 Year 2008 about Standard of facilities and infrastructure of Vocational High School / Madrasah Aliyah Kejuruan (SMK / MAK) and instrument of verification from BSNP. 1049P2-10 / 11 Year 2010/2011 on the instrument of verification of SMK / MAK on the implementation of vocational practice exam. The results of this study indicate that: (1). The average condition of facilities and infrastructure workshop Stone and Concrete SMK Negeri 5 Surakarta is to meet the requirements listed in PERMENDIKNAS. 40 Year 2008. (2). The average feasibility level of facilities in the workshop of Stone and Concrete Engineering SMK Negeri 5 Surakarta 83\% so categorized in very decent condition. (3). The average feasibility level of infrastructure in the workshop of Stone and Concrete Engineering SMK Negeri 5 Surakarta amounted to $97 \%$ so categorized in very decent condition.
\end{abstract}

Keywords : Feasibility,facilities, infrastructure

\title{
PENDAHULUAN
}

Sekolah Menengah Kejuruan (SMK) merupakan salah satu institusi pendididkan formal tingkat menengah yang berkesinambungan dari sistem pendidikan nasional yang menduduki posisi yang sangat penting untuk mewujudkan komitmen mencerdaskan kehidupan bangsa. Untuk itu pendidikan menengah kejuruan pada dasarnya bertujuan untuk menyiapkan tenaga kerja yang memiliki pengetahuan, ketrampilan dan sikap yang sesuai dengan spesialisasi kejuruan dan persyaratan dunia industri atau dunia usaha.

Salah satu cara menghasilkan tenaga profesional dan mampu mengikuti kemajuan ilmu pengetahuan 
dan teknologi adalah meningkatkan sarana dan prasarana pendidikan. Seperti yang dijelaskan pada Peraturan Menteri Pendidikan Nasional NO.40 Tahun 2008 tentang Standar Kejuruan (SMK) dan Madrasah Aliyah Negeri (MAN).

Sarana dan prasarana sekolah adalah salah satu elemen penting guna meningkatkan kompetensi siswa dalam melakukan proses belajar. Sehingga sarana dan prasarana sekolah perlu dilakukan pengkajian ulang tentang tingkat kelayakan guna proses belajar mengajar bisa dengan baik diterima oleh siswa. Untuk itu apabila terdapat sarana dan prasana yang tidak mencapai nilai kelayakan perlu dilakukan pembaharuan dari sarana dan prasarana tersebut. Dengan demikian diharapkan proses belajar dan mengajar bisa berjalan dengan baik dan dapat meningkatkan tingkat kompetensi siswa.

SMK Negeri 5 Surakarta merupakan salah satu sekolah yang selalu mengutakan mutu pendidikan baik dalam teori maupun praktikum di bengkel kerja. Seiring berkembangnya zaman hal tersebut membuat besarnya animo masyarakat terhadap SMK
Negeri 5 Surakarta, sementara daya penyediaan ruang terbatas.

Dampak yang terjadi adalah bengkel batu dan beton yang sifatnya ruangan terbuka dan berdekatan dengan lahan parkir siswa difungsi gandakan menjadi ruang parkir sepeda motor siswa, tentu saja menjadikan standar kriteria minimal sarana dan prasarana sesuai dengan Permendiknas tidak tercapai. Penyalahgunaan bengkel praktik batu dan beton dikhawatirkan mempengaruhi ruang-ruang pembelajaran yang saat itu kosong sehingga SMK Negeri 5 Surakarta khusus nya Program Keahlian Batu dan Beton memerlukan pengkajian tingkat kelayakan sarana dan prasarana sekolah terutama sarana dan prasarana di bengkel batu dan beton Program Keahlian Teknik Batu dan Beton.

Berdasarkan uraian yang telah dijelaskan diatas bahwa proses belajar mengajar di Program Teknik Batu dan Beton SMK Negeri 5 Surakarta dengan tujuan meningkatkan mutu pendidikan memerlukan banyak dukungan dari berbagai aspek, khususnya untuk ruang lingkup sarana dan prasarana belum memenuhi standar yang diterapkan oleh 
pemerintah yaitu Standar Nasional Pendidikan (SNP).

Berdasarkan yang telah dijelaskan dalam latar belakang masalah diatas, maka dapat dirumuskan masalah penelitian ini: 1) Apakah kondisi sarana dan prasarana Kompetensi Keahlian Teknik Konstruksi Batu dan Beton SMK Negeri 5 Surakarta sesuai dengan standar Peraturan Menteri Pendidikan Nasional No. 40 Tahun 2008? 2) Bagaimanakah tingkat kelayakan sarana Kompetensi Keahlian Teknik Konstruksi Batu dan Beton SMK Negeri 5 Surakarta sesuai dengan standar Peraturan Menteri Pendidikan Nasional No. 40 Tahun 2008? 3) Bagaimanakah tingkat kelayakan sarana Kompetensi Keahlian Teknik Konstruksi Batu dan Beton SMK Negeri 5 Surakarta sesuai dengan standar Peraturan Menteri Pendidikan Nasional No. 40 Tahun 2008?

Berdasarkan paparan di atas maka tujuan penelitian ini adalah sebagai berikut: 1) Mengetahui kesesuaian kondisi sarana dan prasarana di bengkel praktik Kompetensi Keahlian Teknik Konstruksi Batu dan Beton SMK Negeri 5 Surakarta dengan standar Peraturan Menteri Pendidikan
Nasional No. 40 Tahun 2008. 2) Mengetahui tingkat kelayakan sarana Kompetensi Keahlian Teknik Konstruksi Batu dan Beton SMK Negeri 5 Surakarta dengan standar Peraturan Menteri Pendidikan Nasional No. 40 Tahun 2008. 3) Mengetahui tingkat kelayakan sarana Kompetensi Keahlian Teknik Konstruksi Batu dan Beton SMK Negeri 5 Surakarta dengan standar Peraturan Menteri Pendidikan Nasional No. 40 Tahun 2008.

\section{Gambaran Umum Pendidikan Kejuruan}

Dalam Hasbullah (2012: 4) Ki Hajar Dewantara menjelaskan bahwa pendidikan yaitu tuntutan di dalam hidup tumbuhnya anak-anak adapun maksudnya, pendidikan yaitu menuntun segala kekuatan kodrat yang ada pada anak-anak itu, agar mereka sebagai manusia dan sebagai anggota masyarakat dapatlah mencapai keselamatan dan kebahagiaan yang setinggi-tingginya. Dari kutipan-kutipan di atas, dapat disimpulkan bahwa pendidikan merupakan suatu proses pembentukan kecakapan-kecakapan hidup tehadap anak didik agar menjadi 
pribadi dewasa susila yang mampu sepenuhnya bertindak sendiri bagi kesehteraan hidupnya dan bermasyarakat.

\section{Peraturan Menteri Pendidikan} Nasional Nomor 22 Tahun 2006 tentang Standar Isi Untuk Satuan Pendidikan Dasar dan Menengah menerangkan bahwa :

pendidikan kejuruan bertujuan untuk meningkatkan kecerdasan, pengetahuan, kepribadian, akhlak mulia, serta ketrampilan peserta didik untuk hidup mandiri dan mengikuti pendidikan lebih lanjut sesuai dengan program kejuruannya. Agar dapat bekerja secara efektif dan efisien serta mengembangkan keahlian dan ketrampilan, mereka harus memiliki stamina yang tinggi, menguasai bidang keahliannya dan dasar-dasar ilmu pengetahuan dan teknologi, memiliki etos kerja yang tinggi dan mampu berkomunikasi sesuai dengan tuntutan pekerjaanya, serta memiliki kemampuan mengembangkan diri.

Berdasarkan definisi-definisi di atas, dapat di simpulkan bahwa pendidikan kejuruan adalah pendidikan yang memberikan bekal berbagai pengetahuan, ketrampilan dan pengalaman kepada peserta didik sehingga mampu melakukan pekerjaan tertentu yang di butuhkan, baik bagi dirinya, bagi dunia kerja maupun bagi pembangunan bangsanya.

SMK merupakan salah satu jenjang pendidikan kejuruan di tingkat menengah yang mengutamakan pengembangan kemampuan siswa untuk melaksanakan jenis pekerjaan tertentu. Pendidikan kejuruan secara luas mencangkup semua jenis dan bentuk pengalaman belajar yang membantu anak didik mengembangkan kemampuannya dalam suatu bidang tertentu.

Sebagai suatu pendidikan khusus, pendidikan kejuruan direncanakan untuk mempersiapkan peserta didik untuk memasuki dunia kerja, sebagai tenaga kerja produktif yang mampu menciptakan produk unggul yang dapat bersaing di pasar global dan profesional yang memiliki kualitas moral di bidang kejuruannya (keahliannya). Di samping itu, pendidikan kejuruan juga berfungsi mempersiapkan siswa menguasai ilmu pengetahuan dan teknologi (IPTEK).

\section{Pembelajaran Praktik Bengkel}

Beberapa

pengertian pembelajaran praktik bengkel menurut 
para ahli dapat diuraikan sebagai berikut:

Pembelajaran praktik merupakan suatu proses untuk meningkatkan keterampilan peserta didik dengan menggunakan berbagai metode yang sesuai dengan ketrampilan yang diberikan dan peralatan yang digunakan. Dengan kata lain pembelajaran praktik merupakan suatu proses pendidikan yang menggunakan media pembelajaran berupa peralatan ataupun alat peraga untuk melakukan suatu keterampilan (Woto, 2001 : 74). Menurut Amrozi ( 2011: 33) mendefinisikan bahwa melakukan proses praktikum bengkel berarti membelajarkan para siswa secara terkondisi, mereka belajar dengan mendengar, menyimak, melihat, meniru apa-apa yang dikonfirmasikan oleh guru atau fasilitator di depan kelas. Dengan belajar seperti ini mereka memiliki perilaku sesuai dengan tujuan yang telah direncanakan guru sebelumnya.

\section{Tinjauan Tentang Sarana dan Prasarana Praktik Bengkel}

Sarana adalah segala sesuatu yang dipakai sebagai alat dalam mencapai maksud atau tujuan ( Kamus Besar Bahasa Indonesia, 2010: 999).

Prasarana adalah segala sesuatu yang merupakan penunjang utama terselenggaranya suatu proses (usaha, pembangunan,proyek,dsb) (Kamus Besar Bahasa Indonesia, 2002: 893).

Sarana dan prasarana pendidikan merupakan salah satu standar Nasional Pendidikan yang harus dipenuhi oleh penyelenggara satuan pendidikan, sehingga melengkapi sarana dan prasarana menjadi hal yang mutlak, hal tersebut sesuai dengan Undang-Undang Sistem Pendidikan Nasional (SISDIKNAS) No. 20 Tahun 2003 pasal 45 yang berbunyi: "Setiap satuan pendidikan formal dan non formal menyediakan sarana dan prasarana yang memenuhi keperluan pendidikan sesuai dengan pertumbuhan dan perkembangan potensi fisik, kecerdasan intelektual, sosial, emosional dan kejiwaan peserta didik".

Undang-Undang SISDIKNAS No. 20 Tahun 2003 pasal 45 di atas diperjelas dengan Peraturan Pemerintah No.19 Tahun 2005 pasal 42 ayat 1, yang berbunyi : "Setiap satuan pendidikan wajib memiliki sarana yang meliputi : perabot, peralatan pendidikan, media 
pendidikan, buku, dan sumber belajar lainnya, bahan habis pakai, serta perlengkapan lain yang diperlukan untuk menunjang proses pembelajaran yang teratur dan berkelanjutan."

\section{Silabus Pendidikan Praktik}

Silabus adalah garis besar, ringkasan, ikhtisar, atau pokok-pokok isi/materi pembelajaran (Salim, 1987: 98). Silabus merupakan seperangkat rencana serta pengaturan pelaksanaan pembelajaran dan penilaian yang disusun secara sistematis memuat komponen-komponen yang saling berkaitan untuk mencapai penguasaan kompetensi dasar. Menurut Kurikulum 2013 Silabus adalah rencana pembelajaran pada suatu kelompok mata pelajaran/tema tertentu yang mencakup stan standart kompetensi, kompetensi dasar,materi pembelajaran, indikator, penilaian, alokasi waktu, dan sumber/bahan/alat belajar.

\section{Standar Fasilitas Praktik}

Peraturan Menteri Pendidikan Nasional Nomor 40 Tahun 2008 berisi tentang Standar Sarana Dan Prasarana Untuk Sekolah Menengah Kejuruan/Madrasah Aliyah Kejuruan
(SMK/MAK). Peraturan Pemerintah No. 40 tahun 2008 ini memuat semua standar minimal untuk ruang praktik pada program keahlian Teknik Konstruksi Batu Beton yaitu (1) Luas minimum ruang praktik, (2) Rasio perpeserta didik, (3) Daya tampung ruang, (4) Luas ruang penyimpanan dan instruktur, (5) Perabot ruang praktik, (6) Peralatan yang terdapat di ruang praktik, (7) Media pendidikan yang terdapat di ruang praktik,dan (8) Perlengkapan lain yang terdapat di ruang praktik.

Peraturan Badan Standar Nasional Pendidikan (BSNP) No. 1049-P2-10/11 Mengenai Instrumen Verifikasi SMK Penyelenggara Ujian Praktik Kejuruan, Peraturan Badan Standar Nasional Pendidikan (BSNP) Mengenai Instrumen Verifikasi SMK Penyelenggara Ujian Praktik Kejuruan, berisi tentang standar persyaratan peralatan utama, standar persyaratan peralatan pendukung, standar persyaratan tempat/ruang, persyaratan penguji. Peraturan ini digunakan untuk mengevaluasi kelayakan sekolah dalam melaksanakan ujian praktik kejuruan Teknik Konstruksi Batu dan Beton. 


\section{METODOLOGI PENELITIAN}

Penelitian ini dilaksanakan di SMK Negeri 5 Surakarta yang terletak di Jalan L.U. Adisucipto No. 42 Laweyan Surakarta. Penelitian dikhususkan pada bengkel praktik bangunan Kompetensi Keahlian Teknik Konstruksi Batu Beton.

Penelitian tentang analisis sarana praktik bengkel bangunan terhadap nilai hasil praktik siswa pada Kompetensi Keahlian Teknik Konstruksi Batu dan Beton di SMK N 5 Surakarta ini merupakan penelitian deskriptif kualitatif. Narbuko dan Achmadi (2012: 44) menjelaskan bahwa penelitian deskriptif yaitu penelitian yang berusaha untuk menuturkan pemecahan masalah yang ada sekarang berdasarkan data-data dengan menyajikan data, menganalisis data dan menginterpretasi.

Pendekatan pada penelitian ini menggunakan data berupa hasil wawancara kepada informan,observasi langsung dan dokumentasi. Selanjutnya data hasil penelitian bengkel kejuruan SMK Negeri 5 Surakarta dibandingkan baik itu kesesuainnya dengan standar yang ada pada Lampiran Peraturan
Menteri Pendidikan Republik Indonesia No. 40 Tahun 2008 Mengenai Standar Sarana dan Prasarana Sekolah Menengah Kejuruan/Madrasah Aliyah Kejuruan (SMK/MAK) dan standar dari BSNP No. 1049-P2 Tahun 2010/2011 Mengenai Instrumen Verifikasi SMK Tentang Penyelenggara Ujian Praktik Kejuruan Tahun 2010/2011.

Teknik pengumpulan data yang digunakan yaitu dengan wawancara, observasi langsung, dokumentasi foto sarana dan prasarana, daftar inventaris sarana dan prasarana.

Teknik uji validitas data yang dipakai dalam penelitian ini adalah validitas konstrak. Karena instrumen yang digunakan berupa nontest sehingga cukup memenuhi validitas konstrak saja. Validitas konstrak dapat berupa pendapat dari para ahli (judgement expert). Teknik yang dilakukan pada pengujian validasi kontruksi melalui analisis instrumen untuk mengukur solusi terhadap sarana praktik bengkel yang tersedia.

Teknik analisis data yang digunakan penelitian ini adalah teknik analisis model interaktif yang diungkapkan oleh Sugiyono (2006). 
Model analisis ini terdiri atas empat tahap pokok yaitu pengumpulan data, reduksi data, sajian data, dan kesimpulan.

Dalam penyajian data menggunakan statistik desktiptif, , dimana nanti nya data yang ada akan ditabulasi, dihitung persentase tingkat kelayakan nya dengan cara membagi skor riil dengan skor acuan yang dikalikan dengan seratus persen. Persentase tersebut sebagai acuan untuk mendeskripsikan sarana praktik bengkel bangunan pada Kompetensi Keahlian Teknik Konstruksi Batu dan Beton. Aspek yang dideskripsikan meliputi perabot ruang praktik, peralatan praktik dan media pembelajaran. Proses perhitungan persentase dilakukan dengan cara mengalikan hasil bagi skor riil dengan skor ideal dengan seratus persen (Sugiyono, 2010:133).

Dalam penelitian ini kriteria pencapaian sarana antara lain sangat layak, layak, kurang layak dan tidak layak seperti yang dipaparkan dalam tabel berikut:
Tabel 1 Kriteria Penilaian Untuk Sarana Praktik

\begin{tabular}{ccc}
\hline Bobot & Definisi & Kriteria \\
& & \\
\hline 4 & Sangat Layak & $76 \%-100 \%$ \\
\hline 3 & Layak & $51 \%-75 \%$ \\
\hline 2 & Kurang Layak & $26 \%-50 \%$ \\
\hline 1 & Tidak Layak & $0 \%-25 \%$ \\
\hline
\end{tabular}

\section{HASIL PENELITIAN DAN PEMBAHASAN}

Hasil penelitian ini bertujuan untuk mengetahui kelayakan sarana dan prasarana ruang praktik pada kompetensi keahlian Teknik Konstruksi Batu dan Beton di SMK Negeri 5 Surakarta. Kelayakan dianalisis dengan membandingkan standar Permendiknas No. 40 Tahun 2008 dan BSNP No. 1049-P2-10/11 Tahun 2010/2011 Mengenai Instrumen Verifikasi SMK Tentang Penyelenggara Ujian Praktik Kejuruan Tahun 2010/2011 sesuai kondisi peralatan di lapangan.

Sarana dan prasarana yang ditinjau dalam penelitian ini berupa luasan bengkel batu dan beton, perabot bengkel, peralatan utama, peralatan pendukung, media pembelajaran dan perlengkapan lain. 
Berdasarkan kesesuaian terhadap standar Permendiknas No. 40 Tahun 2008, tingkat kelayakan sarana perabot di ruang praktik bengkel batu dan beton SMK Negeri 5 Surakarta untuk kapasitas kelas 28 siswa sesuai keadaan di lapangan pada kelas XI tahun ajaran 2015/2016 memperoleh rata-rata kelayakan $100 \%$ dan masuk dalam kategori sangat layak. Jenis perabot dalam bengkel batu dan beton meliputi meja kursi guru, lemari simpan alat dan bahan.

Perolehan persentase rata-rata untuk peralatan utama yaitu sebesar $64 \%$, sehingga masuk dalam kategori layak. Peralatan yang masuk dalam kategori kurang layak adalah selang plastik dan kakak tua dengan persentase masing-masing kelayakan peralatan sebesar $40 \%$ dan $32 \%$ dari standar. Sedangkan untuk peralatan yang dikategorikan tidak layak adalah roskam baja. Untuk kondisi peralatan praktik hampir semuanya dalam keadaan baik dan siap digunakan, hal tersebut karena setiap semester diadakan pengadaan peralatan-peralatan yang dibutuhkan ke bagian Sarana Prasarana (Sarpras) SMK Negeri 5 Surakarta. Jumlah total kebutuhan tersebut berdasarkan standar dari BSNP mengenai Instrumen Verifikasi Penyelenggara Ujian SMK No. 1049-P2-10/11. Berdasarkan observasi di lapangan, praktik siswa dilakukan secara individual maka untuk jumlah peralatan juga disesuaikan dengan jumlah siswa yang melaksanakan praktik.

Sedangkan untuk peralatan pendukung perolehan persentase ratarata untuk yaitu sebesar $76 \%$, sehingga masuk dalam kategori sangat layak, peralatan pendukung yang tidak layak adalah gergaji besi, jadi siswa yang akan menggunakan alat tersebut harus bergantian dengan siswa yang lain nya. Untuk peralatan pendukung yang lain sudah memenuhi standar Instrumen Verifikasi SMK Penyelenggara Ujian Praktik Kejuruan yang dikeluarkan oleh BSNP.

Berdasarkan kesesuaian terhadap standar Permendiknas No. 40 Tahun 2008, tingkat kelayakan sarana media pembelajaran dan perlengkapan lain yang berupa papan tulis, kotak kontak dan tempat sampah di ruang praktik bengkel batu dan beton SMK Negeri 5 sesuai keadaan di lapangan pada kelas XI tahun ajaran 2015/2016 memperoleh 
rata-rata kelayakan $100 \%$ dan masuk dalam kategori sangat layak.

Tabel 2. Tingkat Kelayakan Sarana di Ruang Praktik Bengkel Batu dan Beton SMK Negeri 5 Surakarta

\begin{tabular}{ccc}
\hline Jenis & $\begin{array}{c}\text { Kelaya } \\
\text { kan }\end{array}$ & Ket \\
\hline Perabot & $76 \%$ & $\begin{array}{c}\text { Sangat } \\
\text { layak }\end{array}$ \\
\hline Peralatan utama & $64 \%$ & Layak \\
\hline $\begin{array}{c}\text { Peralatan pen- } \\
\text { dukung }\end{array}$ & $76 \%$ & Sangat \\
\hline $\begin{array}{c}\text { Media pembela- } \\
\text { jaran }\end{array}$ & $100 \%$ & Sangat \\
\hline Perlengkapan & & Sangat \\
lain & $100 \%$ & layak \\
\hline Persentase & rata-rata & untuk
\end{tabular}

pencapaian kelayakan sarana praktik bengkel batu dan beton mencapai $83 \%$ sehingga apabila diinterpretasikan masuk dalam kategori sangat layak. Sehingga sarana yang tersedia di ruang bengkel sudah dapat menunjang proses pembelajaran siswa

Prasarana dalam bengkel batu dan beton Berdasarkan Permendiknas No.40 Tahun 2008 luas minimum ruang praktik Program Keahlian Batu dan Beton adalah 304 meter persegi untuk menampung 32 peserta didik, yang meliputi area kerja batu dan beton 128 meter persegi, ruang pemasangan finishing 128 meter persegi, ruang penyimpanan dan instruktur 48 meter persegi. Ruang praktik harus memenuhi rasio minimum luas ruang praktik 8 meter persegi/peserta didik. Sedangkan data yang dimiliki bengkel batu dan beton SMK Negeri 5 Surakarta adalah sebagai berikut :

$\begin{array}{ll}\text { Kapasitas } & : 28 \text { peserta didik } \\ \text { Panjang } & : 12 \text { meter } \\ \text { Lebar } & : 18 \text { meter } \\ \text { Luas } & : 216 \text { meter persegi } \\ \text { Rasio luas } & =\text { Luas } / \text { Kapasitas } \\ & =216 / 28 \\ & =7,7 \mathrm{~m} 2 / \text { peserta didik }\end{array}$

Dari data yang didapat tersebut di atas, prasarana untuk bengkel batu dan beton SMK Negeri 5 Surakarta Program Keahlian Batu dan Beton di SMK Negeri 5 Surakarta memperoleh persentase kelayakan sebesar 97\%. Hal ini menandakan bahwa prasarana yang dimiliki bengkel batu dan beton SMK Negeri 5 Surakarta Program Keahlian Batu dan Beton di SMK Negeri 5 Surakarta sudah sangat memenuhi persyaratan yang tertuang pada Permendiknas No.40 Tahun 2008. 


\section{SIMPULAN,IMPLIKASI,SARAN}

Kondisi rata-rata sarana dan prasarana pada Program Keahlian Teknik Batu dan Beton SMK Negeri 5 Surakarta adalah memenuhi syarat yang tercantum pada Lampiran Permendiknas No. 40 Tahun 2008. Tingkat

kelayakan prasarana di bengkel praktik Kompetensi Keahlian Teknik Konstruksi Batu dan Beton SMK N 5 Surakarta pada saat ini dalam keadaan sangat layak dan memiliki tingkat pencapaian kelayakan $97 \%$ dari standar yang sudah di tetapkan.

Tingkat kelayakan sarana di bengkel praktik Kompetensi Keahlian Teknik Konstruksi Batu dan Beton SMK N 5 Surakarta pada saat ini sudah dalam keadaan sangat layak dan memiliki tingkat pencapaian kelayakan $83 \%$ dari standar yang sudah ditetapkan.

Dari simpulan yang di dapat maka implikasi nya adalah : Dengan memenuhi tingkat kelayakan prasarana pada Program Keahlian Teknik Batu dan Beton SMK Negeri 5 Surakarta berdasarkan ketentuan pada Permendiknas No.40 Tahun 2008 maka pelaksanaan praktik bisa berjalan dengan lancar, siswa bisa praktik sesuai dengan tujuan pembelajaran yang akan di capai, suasana akan kondusif, siswa akan lebih nyaman, tidak desakdesakan, penyimpanan alat akan lebih aman. Dengan memenuhi tingkat kelayakan sarana pada Program Keahlian Teknik Batu dan Beton SMK Negeri 5 Surakarta berdasarkan ketentuan pada Permendiknas No.40 Tahun 2008 maka pelaksanaan praktik bisa berjalan dengan lancar, siswa bisa menguasai kompetensi yang akan di capai sesuai RPP, praktik bisa lebih cepat selesai, siswa bisa mahir menggunakan sarana sesuai dengan jobsheet, peralatan praktik bisa lebih tertata.

Berdasarkan kesimpulan di atas, maka terdapat saran-saran yang di temukan oleh peneliti yang perlu dipertimbangkan, yaitu : Sekolah hendaknya melakukan pendataan kelengkapan sarana untuk kegiatan praktik terutama pada peralatan dan perabot di bengkel praktik. Beberapa peralatan yang jumlahnya terbatas dan masih kurang, hendaknya memperoleh prioritas dalam pengadaan, pengembangan maupun perbaikan alatalat untuk masa yang akan datang. 
Pihak sekolah hendaknya lebih memperhatikan dan meningkatkan sarana dan prasarana pada ruang bengkel praktik batu dan beton sehingga tujuan pembelajaran dapat tercapai secara maksimal. Pihak sekolah hendaknya melengkapi sarana yang jumlah nya belum memenuhi standar. Pada peralatan utama yang jumlah nya belum memenuhi standar meliputi selang plastik, roskam, kakak tua. Peralatan pendukung yang jumlah nya belum memenuhi standar meliputi sekop, gergaji kayu, mesin pemotong bata.

Pihak sekolah hendaknya memperhatikan fungsi bengkel batu dan beton dan melarang siswa untuk meletakan motor di bengkel tersebut.

\section{DAFTAR PUSTAKA}

Badan Pengembangan dan Pembinaan Bahasa. (2010). Kamus Besar Bahasa Indonesia

Badan Standar Nasional Indonesia. (2012). Instrumen Verifikasi SMK Penyelenggara Ujian Praktik Kejuruan No. 1049-P2-10/11.

Departemen Pendidikan Nasional, 2003. Undang-Undang Nomor 20 Tahun 2003, Tentang Sistem Pendidikan Nasional, Jakarta: Depdiknas
Hasbullah. (2012). Dasar-Dasar Ilmu Pendidikan. Jakarta: PT. Raja Grafindo.

Peraturan Menteri. (2008). Lampiran Peraturan Menteri Pendidikan Nasional Tahun 2008 Tanggal 31 Juli 2008 Standar Sarana dan Prasarana Sekolah Menengah Kejuruan/Madrasah Aliyah Kejuruan (SMK/MAK).

Peraturan Pemerintah. (2005). Peraturan Pemerintah Republik Indonesia No. 19 Tahun 2005 Tentang Standar Sarana dan Prasarana.

Pusat Kurikulum, Balitbang Depdiknas, (2003). Model Pelatihan Dan Pengembangan Silabus.Jakarta.

Sugiyono. (2010).Metode Penelitian Pendidikan. Bandung: Alfabeta.

Suharsimi Arikunto. (2010). Prosedur Penelitian. Jakarta: Rineka Cipta.

Tim Skripsi. (2016). Pedoman Penulisan Skripsi. Surakarta: Fakultas Keguruan dan Ilmu Pendidikan UNS.

Undang-Undang Sistem Pendidikan Nasional. (2003). UndangUndang Sistem Pendidikan Nasional. 